\title{
Frequency of Instrumentation in Lumbar Spinal Stenosis and Lumbar Disc Herniation
}

\author{
Seyyed Ebrahim Hejazian ${ }^{1}$, Mersedeh Dadpour ${ }^{2 *}$ \\ ${ }^{1}$ MD, Assistant Professor of Neurosurgery, Shahid Beheshti Hospital, Babol University of Medical Sciences, Babol, Iran \\ ${ }^{2} \mathrm{MD}$, General Physician, Shahid Beheshti Hospital, Babol University of Medical Sciences, Babol, Iran \\ *Corresponding Author Address: Shahid Beheshti Hospital, Keshvari Square, Shahid Sargord Ghasemi Street, Babol, Mazandaran, Iran. Tel:+981132252071. \\ Fax:+981132251664. Postal Code: 8145147166. Email: mersedeh_dadpour@yahoo.com
}

Article Type: Research Article

Received: April 11, 2016, Last Revised: September 10, 2016, Accepted: September 11, 2016

\section{Abstract}

Background \& Aim: Lumbosacral pain is extremely common as age increases. Spinal instrumentation is sometimes recommended for lumbar canal stenosis and disk herniation surgery. This study aimed at studying the frequency of instrumentation in patients referring to our center.

Methods \& Materials/Patients: This retrospective cross-sectional study included 1200 patients with low back and/or radicular pain who had referred to the Shahid Beheshti and Ayatallah Roohani hospitals from 2013 to 2014 in Babol city. Data were analyzed by t-test and chisquare using SPSS (Version 20).

Results: In this study, 150 of 1200 patients needed surgery for lumbar canal stenosis and/or disk herniation (mean age of $42.21 \pm 11.41$ years old, ranging from 26-69). Of all patients, 76 were men (50.7\%) and 74 women (49.3\%). L4-L5 was the most involved level. There was a significant relationship between pathology and gender $(\mathrm{p}<001)$. At some levels, either men or women were involved. Moreover, 55 patients $(36.7 \%)$ underwent surgery with instrumentation and 95 patients $(63.3 \%)$ without instrumentation. Complete improvement was reported in 102 patients $(68 \%)$. No significant relationship was observed between the degree of improvement and surgery technique and gender $(p=0.78$, $\mathrm{p}=0.72$ ).

Conclusion: Most patients (63.3\%) underwent surgery without instrumentation and about one third needed fixation during surgery.

Keywords: Spinal Stenosis; Disc Herniation; Instrumentation

Please cite this paper as: Hejazian S.E, Dadpour M. Frequency of Instrumentation in Lumbar Spinal Stenosis and Lumbar Disc Herniation. Iran. J. Neurosurg. 2016;2(2):6-9.

\section{Introduction}

Spinal stenosis is narrowing of spinal canal around soft tissue and bone which endangers nerves (1). It is very common in radiographic findings and inflicts people in their fifth and sixth decades of life (2). It can be acquired or rarely congenital. The prevalence of congenital spinal stenosis is 5/100000 with remarkable limping $(3,4)$. These patients usually complain of gluteal and back pain $(5,6)$. The symptoms worsen as one walks or stands, while sitting and leaning forward settle the pain (7). Due to slow improvement and accompanying complications, the disease needs prompt and proper treatment (8). Although some patients improve after nonsurgical interventions (medications, physiotherapy and medical belt use), the effect of conservative treatment is limited and not helpful in patients with severe condition (9). Surgery is usually the best choice for them $(10,11)$. Evidence has also proved that after failure of conservative treatment for about six months, surgery would be the effective solution $(12,13)$. Different surgeries are recommended depending on the severity of the complications. The most common type of spine surgery is decompressive laminectomy (14) in which vertebral lamina is extracted to create more space for the neurons. Neurosurgeons may perform laminectomy with or without vertebrae fusion or removing a part of disc. If spondylolisthesis or scoliosis occurs, instrumentation may be recommended. Different devices such as wires, screws or rods are used to facilitate fusion and support instable areas of spine (15-16). The aim of our study was to evaluate the frequency of instrumentation use in patients with lumbar canal stenosis and/or disk herniation who referred to Shahid Beheshti and Ayatallah Roohani hospitals in Babol city in Mazandaran province, north of Iran.

\section{Methods and Materials/Patients}

This cross-sectional study was conducted on patients with lumbar discherniation and lumbar stenosis who had referred to elective wards. Patients suffering from trauma, tumor, infectious disease, rheumatic and spondylolisthesis were excluded. All information of patients was recorded in a checklist including demographic characteristics, surgery technique, pathology, degree of improvement and up to 18 months follow-up. Written consent forms were obtained from all patients. In addition to clinical examination, simple radiography and lumbosacral MRI were performed. According to MRI and dynamic lumbosacral x-ray (flexion and extension), patients were operated by a neurosurgeon with instrumentation i.e. pedicular screw and rod fixation or without instrumentation through nerve decompression. Visual analogue scale (VAS) was then used to determine the degree of improvement. In this scale, if the level of pain was less than 4 complete improvement, if between 5-8 mild improvement and if upper than 8 no improvement was recorded for patient. Data were finally analyzed using SPSS (version 20), t-test and chi-square. 


\section{Results}

Out of 1200 patients who had been referred to the clinic, 150 ones needed surgery after clinical and paraclinical examination, so they were enrolled in the study. The mean age of patients was $42.21 \pm 11.41$ years old ranging from 26 to 69 . No statistical significant difference was observed between mean age of men $(40.71 \pm 10.67)$ and women $(43.76 \pm 12.01)(\mathrm{p}=0.1)$.

In these patients, the most frequent lumbar disc herniation and spinal stenosis were at the L4-L5 (42.4\%), L5-S1 (14.7\%) and L3L4-L5-S1 (14.7\%).

This study found a significant relationship between pathology and gender $(\mathrm{p}<0.001)$. At some levels, either men or women were involved (Table 1).

Table 1. Relationship between Pathology and Gender

\begin{tabular}{|c|c|c|}
\hline \multirow{2}{*}{ Pathology Level } & \multicolumn{2}{|c|}{ Gender } \\
\cline { 2 - 3 } & N (\%) & $\begin{array}{c}\text { Women } \\
\text { N (\%) }\end{array}$ \\
\hline L5-S1 & $11(50)$ & $11(50)$ \\
\hline L4-L5 & $21(58.3)$ & $15(41.7)$ \\
\hline L3-L4 & - & $7(100)$ \\
\hline L2-L3 & $2(20)$ & $8(80)$ \\
\hline L4-L5-S1 & $4(44.4)$ & $5(55.6)$ \\
\hline L3-L4-L5 & $9(52.9)$ & $8(47.1)$ \\
\hline L3-L4-L5-S1 & $8(36.4)$ & $14(63.3)$ \\
\hline L2-L3-L4 & $12(66.7)$ & $6(33.3)$ \\
\hline L2-L3-L4-L5 & $9(100)$ & - \\
\hline
\end{tabular}

Moreover, 55 patients (36.7\%) underwent surgery with instrumentation and 95 patients $(63.3 \%)$ without instrumentation. During up to 18 months of follow up, 102 patients $(68 \%)$ had complete and 48 mild improvement $(0.32 \%)$. No significant relationship was seen between the level of improvement and the surgery technique. Interestingly, most of the patients with complete improvement had been operated without instrumentation $(\mathrm{p}=0.78)$ (Table 2).

Table 2. Relationship between Surgery Technique and Improvement

\begin{tabular}{|c|c|c|}
\hline Improvement & \multicolumn{2}{|c|}{ Surgery Technique } \\
\hline & $\begin{array}{c}\text { With } \\
\text { Instrumentation } \\
\mathbf{N}(\%)\end{array}$ & $\begin{array}{c}\text { Without } \\
\text { Instrumentation } \\
\mathbf{N}(\%)\end{array}$ \\
\hline $\begin{array}{c}\text { Complete } \\
\text { Improvement }\end{array}$ & $27(49.1)$ & $75(78.9)$ \\
\hline $\begin{array}{c}\text { Incomplete } \\
\text { Improvement }\end{array}$ & $28(50.9)$ & $20(21.1)$ \\
\hline
\end{tabular}

This study showed that complete improvement was higher in men than women (most of whom had mild improvement). However, this association was not statistically significant $(\mathrm{p}=0.72)$. The results revealed a significant relationship between surgery technique and level of pathology $(\mathrm{p}<0.001)$ (Table 3$)$.
Table 3. Relationship between Pathological Level and Surgery Technique

\begin{tabular}{|c|c|c|}
\hline \multirow{2}{*}{$\begin{array}{c}\text { Pathology } \\
\text { Level }\end{array}$} & $\begin{array}{c}|c| \\
\text { with Instrumentation } \\
\text { N (\%) }\end{array}$ & $\begin{array}{c}\text { Surgery Technique } \\
\text { Instrumentation } \\
\text { N (\%) }\end{array}$ \\
\cline { 2 - 3 } & $2(9.1)$ & $20(90.9)$ \\
\hline L5-S1 & $7(19.4)$ & $29(80.6)$ \\
\hline L4-L5 & $3(42.9)$ & $4(57.1)$ \\
\hline L3-L4 & $8(80)$ & $2(20)$ \\
\hline L2-L3 & $1(11.1)$ & $8(88.9)$ \\
\hline L4-L5-S1 & $3(17.6)$ & $14(82.4)$ \\
\hline L3-L4-L5 & $11(50)$ & $11(50)$ \\
\hline L3-L4-L5-S1 & $11(61.1)$ & $7(38.9)$ \\
\hline L2-L3-L4 & $9(100)$ & - \\
\hline L2-L3-L4-L5 & & \\
\hline
\end{tabular}

\section{Discussion}

Mean age of patients was $42.21 \pm 11.41$ years old in this study, which is similar to a study by Mashhadi Nezhad (mean age $=43$ years old) (17). Moreover, Molaiee et al. (2007) reported the mean age of lumbar disc herniation in Kordestan equal to 41 years old (18). According to prior research, disc herniation and spinal stenosis at different levels of pathology can limit people's activity, especially under 45 years of age (19). Most often, the disease affects young people in working ages, having remarkable economic impact as well (20).

In the present study, $51 \%$ of patients were men and $49 \%$ women. Yabuki et al. (2013) showed that $47.4 \%$ of men and $52.6 \%$ of women had spinal stenosis (21). Tabatabaei et al. (2012) in their study reported a higher number of male than female patients (45/1). Men are exposed to more mechanical tensions than women (22). However, several researches have suggested an equal prevalence of disc herniation and spinal stenosis in men and women (23).

We did not find any significant difference between the prevalence of disc herniation or spinal stenosis in the two groups of men and women. Similarly, Yabuki et al. (2013) reported no significant differences between men and women in terms of age (21). In another study, the prevalence of disc herniation and spinal stenosis was the same in both sexes (23).

In the present research, pathological considerations showed L4-L5 and L5-S1 as the highest involved levels. Similarly, Branden berg and Traynelis (1999) reported the same levels in $90 \%$ of cases. Several other studies published similar findings $(17,18,24-28)$. In fact, upper lumbar spine and extra-foraminal space are proportionately larger than the lower lumbar levels, so high mobility leads to early degeneration and herniation of the disc (29). Perhaps considering ergonomic principles in designing equipment and instruments can avoid damages to lumbar vertebral disc at different levels (30).

In our case, most of 150 surgery candidates were operated without instrumentation. Since 1934, surgery is the common standard treatment for lumbar radiculopathy due to prolapsed disc (31) and have yielded good results $(32,33)$. However, annual government costs on diagnosis, treatment and rehabilitation resulting from spinal stenosis and lumbar disc herniation are heavy (34). Iran is no exception. Discovering the causes of this problem as well as prevention and surgery with or without instrumentation can 
be very useful to reduce the government costs and help the patients have earlier return to their occupation and daily routines (35).

We found $68 \%$ of patients with complete improvement after surgery. Mashhadi Nezhad et al. (2011) reported 94\% improvement (17). In a study by Mobini et al. (2003), most patients with spinal stenosis decompression had improvement in lower limbs and complete satisfaction (36).

Complete improvement was seen more in men than women in our study. Other researchers proved that better surgical outcome correlated with male sex, higher education level, high income and better psychological status (37-39). Furthermore, the main cause of disease played an important role in patient's recovery (40). Some of these risk factors included the presence of trauma or injury in spine, weakness in the annulus, lifting heavy objects, exposure to high seismic waves and smoking $(30,41)$.

\section{Conclusion}

The results of this study showed that the prevalence of stenosis and herniation was the same in ages under 40 in both men and women. Most patients $(63.3 \%)$ underwent surgery without instrumentation. It seems that raising awareness and recognizing the appropriate surgery techniques for spinal stenosis can help these patients for faster return to day life and social activities. Further case-control studies are suggested to achieve these aims.

\section{Acknowledgments}

This study is extracted from a doctoral thesis in Babol University of Medical Sciences. The authors would like to offer their special thanks to Clinical Research Development Unit of Shahid Beheshti University of Medical Sciences, Tehran.

\section{Funding}

None.

\section{Conflicts of Interest}

The authors declare that they have no conflicts of interest.

\section{Authors' Contribution}

Seyyed Ebrahim Hejazian supervised the whole process of performing the research and co-authored this article. Mersedeh Dadpour collected the data and wrote the manuscript.

\section{References}

1. Ishimoto Y, Yoshimura N, Muraki S, Yamada H, Nagata K, Hashizume H, et al. Associations between radiographic lumbar spinal stenosis and clinical symptoms in the general population: the Wakayama Spine Study. Osteoarthritis Cartilage. 2013; 21: 783-788. doi: 10.1016/j.joca.2013.02.656 PMID:23473979.

2. Lotfinia I, Ayermelo H, Afsari F. Short-term study results in a group of patients over age 60 suffer from lumbar spinal stenosis. Medical Journal of Tabriz University of Medical Sciences. 2010; 31(3): 85-9.

3. Azimi P, Rezamohammadi H, Nayebaghaei H, Mohseni M. The results of laminectomy on morphological MRI features. Journal Shahid Beheshti Medical University Tehran. 2012; 36(4): 183-8.

4. Mobini B, Nabizadeh N. Results of Laminotomy in Lumbar Canal Stenosis. Journal of bone and joint surgery Iran. 2003(5):13-20.

5. Kalichman L, Guermazi A, Li L, Hunter DJ. Association between age, sex, BMI and CT-evaluated spinal degeneration features. J Back Musculoskelet Rehabil. 2009; 22:189-95

6. Kalichman L, Kim DH, Li L, Guermazi A, Hunter DJ. Computed tomographyevaluated features of spinal degeneration: prevalence, intercorrelation, and association with self-reported low back pain. Spine J. 2010; 10: 200-8.

7. Saeidian SR, Zeinali M, Teimoori A, Latifi SM. Evaluating the frequency of hamstrings muscle Pain and tightness in Patients suffering from lumbosacral spinal Stenosis. Journal of Mashhad University of Medical Sciences. 2014; 57(4): 609-15. 8. Postacchini F. Surgical management of lumbar spinal stenosis. Spine (Phila Pa 1976). 1999; 24(10): 1043-7.

9. Niggemeyer O, Strauss JM, Schulitz KP. Comparison of surgical procedures for degenerative lumbar spinal stenosis: a meta-analysis of the literature from 1975 to 1995. European spine journal . 1997; 6(6): 423-9.

10. Johnsson KE, Rosen I, Uden A. The natural course of lumbar spinal stenosis. Clinical orthopaedics and related research. 1992; (279): 82-6.

11. You JJ, Bederman SS, Symons S, Bell CM, Yun L, Laupacis A, et al. Patterns of care after magnetic resonance imaging of the spine in primary care. Spine. 2013; 38: 51-59. doi: 10.1097/BRS. 0b013e3182611182 PMID: 22652596

12. Kovacs FM, Urrútia G, Alarcón JD. Surgery versus conservative treatment for symptomatic lumbar spinal stenosis: a systematic review of randomized controlled trials. Spine. 2011; 36: E1335-1351. doi: 10.1097/BRS.0b013e31820c97b1 PMID: 21311394.

13. May S, Comer C. Is surgery more effective than non-surgical treatment for spinal stenosis, and which non-surgical treatment is more effective? A systematic review. Physiotherapy. 2013; 99: 12-20. doi:10.1016/j.physio.2011.12.004 PMID: 23219644.

14. Amini J, Mazloomi M, Reyhani A. Evaluation of Surgical Laminectomy in 14 Cases with Lumbar Spinal Stenosis. Journal of bone and joint surgery Iran. 2004(5):21-4

15. Farzanegan $\mathrm{G}$. The results of lumbar fusion using pedicle screws in patients with Aspvnd Lystzys. Kowsar Medical Journal. 2007; 11(1): 75-80.

16. Erfani M, Nouraei H, Mesbahi A, Toubaei F. Treatment Outcome of Thoracolumbar/Lumbar Scoliosis with Short Segment Anterior Spinal Fusion. Iranian Journal of Orthopaedic Surgery. 2009; 7(3): 99-107.

17. Mashhadi Nezhad H, Samini F, Mashhadi Nezhad S. Comparison of clinical findings and results of open surgury in treatment of primary and recurrent lumbosacral disc herniation. Journal of Birjand University of Medical Sciences. 2011; 17(4): 288-95

18. Molaee M, Mablaghi J. Efficacy of Morphine Injection Versus Sublingual Buprenorphine in Postoperative Pain After Lumbar Laminectomy. The Scientific Journal of Kurdistan University of Medical Sciences. 2008; 12(3): 64-72.

19. Oliphant D. Safety of Spinal Manipulation in the Treatment of Lumbar Disk Herniations: A Systematic Review and Risk Assessment. Journal of Manipulative and Physiological Therapeutics. 2004; 27(3): 197-210.

20. Yorimitsu E, Chiba K, Toyama Y, Hirabayashi K. Long-Term Outcomes of Standard Discectomy for Lumbar Disc Herniation. Spine (Phila Pa 1976). 2001;26 (6): 652-7.

21. Yabuki Sh, Fukumori N, Takegami M. Prevalence of lumbar spinal stenosis, using the diagnostic support tool, and correlated factors in Japan: a population-based study. J Orthop Sci.2013) 18:893-900 . DOI 10.1007/s00776-013-0455-5.

22. Tabatabaei SM, Seddighi AS, Seddighi A, Gholami A, Rahimi Baghdashti H, Shalchizadeh M. World Spinal Column Journal. 2012; 3(3): 80-86.

23. Casal-Moro R, Castro-Menéndez M, Del Campo-Pérez V, Hernández-Blanco M, Jorge-Barreiro FJ. Learning Curve of Microendoscopic Discectomy for the Treatment of Lumbar Disc Herniation. Revista Española de Cirugía Ortopédica y Traumatología (English Edition). 2010; 54(5): 272-9.

24. Jabbari M, Kashani K. Familial predisposition for lumbar degenerative disc disease. Scientific Journal of Hamadan University of Medical Sciences. 2005; 11(2): 35-7.

25. Rijin JC, Klemesto N. Symptomatic and asymptomatic abnormalities in patients with lumbosacral radicular syndrome: Clinical examination compared with MRI Clinical Neurology and eurosurgery. 2006; 108(6): 553-7.

26. Kim KY, Kim YT, Lee CS, Kang JS, Kim YJ. Magnetic resonance imaging in the evaluation of the lumbar herniated intervertebral disc. International orthopaedics. 1993; 17(4): 241-4.

27. Barzin M. MRI findings in patients with spinal stenosis. Guilan University of Medical Sciences. 2011; 20(79): 40-8.

28. Brandenberg GA, Traynelis VC. Disc disease of the spinal column. In: Grossman RG, Loftus CM (eds). Principles of neurosurgery. 2nd ed. 1999, pp: 577-593.

29. Fujii K, Henmi T, Kanematsu Y, Mishiro M, Sakai T. Surgical treatment of lumbar disc herniation in elderly patients. The Journal of bone and joint surgery. British volume. 2003 Nov;85(8):1146-50.

30. Branam BR, Stambough JL. Atypical lumbar disc herniation: a case report. The Spine Journal. 2002; 2(3): 224-6.

31. Padua R, Padua S. Romanini E. Ten to 15 year outcome of surgery for lumbar disc hemiations: radiographic instability and clinical findings. European spine journal. 1999;8(1):70-4

32. Barrios C, Ahmed M, Arrotegui JI, Björnsson A. Clinical factors predicting outcome after surgery for herniated lumbar disc: an epidemiological multivariate analysis.

Journal of spinal disorders. 1990; 3(3): 205-9.

33. Junge A, Dvorak J, Ahrens S. Predictors of bad and good outcome of lumbar disc surgery: a prospecLive clinical study with recommendations for screening to avoid bad outcomes. Spine (Phila Pa 1976). 1995; 20(4): 460-8.

34. Thaler M, Lechner R, Foedinger B, Haid C, Kavakebi P, Galiano K, et al Driving reaction time before and after surgery for disc herniation in patients with preoperative paresis. The Spine Journal. 2015; 15(5): 918-22

35. Wang H, Zhang Z, Zhou Y. Irregular Alteration of Facet Orientation in Lumbar 
Segments: Possible Role in Pathology of Lumbar Disc Herniation in Adolescents. World Neurosurgery. 2016; 86: 321-7.

36. Mobini B, Behtash H, Ameri et all, Patient Satisfaction after Spinal Decompression in Central Degenerative Spinal Stenosis (An early result). Iranian Journal of Orthopaedic Surgery.

(2006): 8-13.

37. Pearson A1, Lurie J, Tosteson T, Zhao W, Abdu W, Weinstein JN. Who should have surgery for spinal stenosis? Treatment effect predictors in SPORT. Spine (Phila Pa 1976). 2012; 37(21): 1791-802.

38. Cobo Soriano J, Sendino Revuelta M, Fabregate Fuente M, Cimarra Diaz I, Martinez Urena P, Deglane Meneses R. Predictors of outcome after decompressive lumbar surgery and instrumented posterolateral fusion. European spine journal. 2010; 19: 1841-8.

39. Sinikallio S, Aalto T, Airaksinen O, Herno A, Kroger H, Viinamaki H. Depressive burden in the preoperative and early recovery phase predicts poorer surgery outcome among lumbar spinal stenosis patients: a one-year prospective follow-up study. Spine (Phila Pa 1976). 2009; 34: 2573-8.

40. Komori H, Okawa A, Haro H, Shinomiya K-i. Factors predicting the prognosis of lumbar radiculopathy due to disc herniation. Journal of Orthopaedic Science. 2002; 7(1): 56-61.

41. Dai L-Y, Zhou Q, Yao W-F, Shen L. Recurrent lumbar disc herniation after discectomy: outcome of repeat discectomy. Surgical Neurology. 2005; 64(3): 226 31 .

\section{Comments}

The authors presented a series of 150 patients with lumbar spinal stenosis or disc herniation who were treated surgically with our without instrumentation. The study suffers from some methodological drawbacks which the readers should pay attention to while reading the paper.

Considering other case series, the frequency of instrumentation and the degree of pain improvement differ significantly between lumbar canal stenosis and disc herniation. Unfortunately, in the current study all cases (either stenosis or disc herniation) were analyzed as one group and so, one should interpret the results cautiously: though the reported rate of $36.7 \%$ instrumentation is produced by similar studies on canal stenosis, the rate is much lower in discopathy patients.

Visual Analog Score (VAS) is a well known scale for reporting pain severity by the patients in different diseases (e.g. lumbar disc herniation). For diseases such as spinal stenosis where activity limitation is more troublesome than pain, functional and life quality scores would be more appropriate for patient evaluation. On the other hand, the authors described patient recovery according to their VAS in their follow up. But we should know that this merely reflects their pain status rather than the recovery rate. Indeed, the authors would require pre-operative VAS to report the "recovery" by comparing pre- and post-operative VAS measures. This ambiguity casts a shadow on the results whose interpretation will be even more difficult when we do not know which patient improved, worsened, or remained unchanged after surgery.

Mohsen Nouri, MD, Board of Directors, Vice Chair of Education Committee, Asian Congress of Neurological Surgeons (ACNS), Neurosurgeon, Gundishapour Academy of Neuroscience (GAN), Ahvazn, Iran 